\title{
Sunlight-driven reduction of silver ion to silver nanoparticle by organic matter mitigates the acute toxicity of silver to Daphnia magna
}

\author{
Zhen Zhang ${ }^{1,2}$, Xiaoya Yang ${ }^{1,2}$, Mohai Shen ${ }^{2}$, Yongguang Yin ${ }^{2, *}$, Jingfu Liu ${ }^{2}$ \\ 1. School of the Environment, Jiangsu University, Zhenjiang 212013, China. E-mail: zhangzhen@ujs.edu.cn \\ 2. State Key Laboratory of Environmental Chemistry and Ecotoxicology, Research Center for Eco-Environmental Sciences, \\ Chinese Academy of Sciences, Beijing 100085, China
}

\section{A R T I C L E I N F O}

\section{Article history:}

Received 12 February 2015

Revised 3 March 2015

Accepted 3 March 2015

Available online 28 May 2015

\section{Keywords:}

Silver nanoparticle

Silver ion

Reduction

Natural organic matter

Acute toxicity

Daphnia magna

\begin{abstract}
A B S T R A C T
Due to the unique antibacterial activities, silver nanoparticles (AgNPs) have been extensively used in commercial products. Anthropogenic activities have released considerable AgNPs as well as highly toxic silver ion $\left(\mathrm{Ag}^{+}\right)$into the aquatic environment. Our recent study revealed that ubiquitous natural organic matter (NOM) could reduce $\mathrm{Ag}^{+}$to AgNP under natural sunlight. However, the toxic effect of this process is not well understood. In this work, we prepared mixture solution of $\mathrm{Ag}^{+}$and AgNPs with varied $\mathrm{Ag}^{+} \%$ through the sunlight-driven reduction of $\mathrm{Ag}^{+}$by NOM and investigated the acute toxicity of the solutions on Daphnia magna. Formation of AgNPs was demonstrated and characterized by comprehensive techniques and the fraction of unconverted $\mathrm{Ag}^{+}$was determined by ultrafiltration-inductively coupled plasma mass spectrometry determination. The formation of AgNPs enhanced significantly with the increasing of solution $\mathrm{pH}$ and cumulative photosynthetically active radiation of sunlight. The toxicity of the resulting solution was further investigated by using freshwater crustacean D. magna as a model and an $8 \mathrm{hr}$-median lethal concentration $\left(\mathrm{LC}_{50}\right)$ demonstrated that the reduction of $\mathrm{Ag}^{+}$by NOM to AgNPs significantly mitigated the acute toxicity of silver. These results highlight the importance of sunlight and NOM in the fate, transformation and toxicity of $\mathrm{Ag}^{+}$and AgNPs, and further indicate that the acute toxicity of AgNPs should be mainly ascribed to the dissolved $\mathrm{Ag}^{+}$from AgNPs.
\end{abstract}

(c) 2015 The Research Center for Eco-Environmental Sciences, Chinese Academy of Sciences. Published by Elsevier B.V.

\section{Introduction}

Silver nanoparticles (AgNPs) have been widely applied in developing biological nanosensors and optoelectronic nanodevices owning to the unique electronic and chemical properties (Kamat, 2002). More importantly, AgNPs are now also widely incorporated in commercial products such as textiles, food packaging, detergents, wound bandage and personal hygiene products (Benn et al., 2010; Benn and Westerhoff, 2008; Ribeiro et al., 2014) for antibacterial and disinfection purposes (Li et al., 2008). During the manufacturing, use and disposal of these commercial products, the discharging of AgNPs is definitely inevitable (Benn et al., 2010; Benn and Westerhoff, 2008; Geranio et al., 2009). These AgNPs will likely enter the aquatic environment, and then, pose threats to the environment and human health (Choi et al., 2008).

\footnotetext{
* Corresponding author.E-mail: ygyin@rcees.ac.cn (Yongguang Yin).
} 
Another silver species, silver ion $\left(\mathrm{Ag}^{+}\right)$, is one of the most toxic metals and has been regulated by the US Environmental Protection Agency (Lam and Wang, 2006). However, high concentration of $\mathrm{Ag}^{+}$could still be observed in industrial wastewater and mine tailings owing to application in electronic, photographic industry and mining (Lasko and Hurst, 1999; Sanudowilhelmy and Flegal, 1992).

Once released into the aquatic environment, AgNPs and $\mathrm{Ag}^{+}$can readily transform, which will affect their transport, fate, bioavailability, and toxicity (Levard et al., 2012). The medium redox potential of silver $\left(\varphi\left(\mathrm{Ag}^{+} / \mathrm{Ag}^{0}\right)=0.80 \mathrm{~V}\right)$ makes both the oxidation of $\mathrm{Ag}^{0}$ and reduction of $\mathrm{Ag}^{+}$possible to occur in aqueous systems (Yu et al., 2013). In addition, the high surface area of nanoscale sized AgNPs further promotes their high reactive behavior in environmental compartments (Angel et al., 2013). Oxidation of AgNPs and releasing $\mathrm{Ag}^{+}$can occur in the presence of dissolved dioxygen and protons, and the $\mathrm{Ag}^{+}$ions releasing rate increases with temperature but decreases with pH increase (Liu and Hurt, 2010; Sotiriou et al., 2012). Oxidative dissolution can also be influenced by peroxidation, AgNPs size, initial AgNP concentration, as well as surface coating (Kittler et al., 2010; Liu et al., 2010). On the other hand, ubiquitous natural organic matter (NOM) in aquatic environments could reduce $\mathrm{Ag}^{+}$into AgNPs, and this process could be accelerated by heating or sunlight irradiation (Adegboyega et al., 2012; Hou et al., 2013; Tang et al., 2015; Yin et al., 2012). Our recent study further demonstrated that $\mathrm{Ag}^{+}$ released via oxidative dissolution of AgNPs could re-reduce into AgNPs in the presence of NOM under sunlight, which could decrease the dissolved $\mathrm{Ag}^{+}$and account for the morphology change of AgNPs in aquatic environments (Yu et al., 2013).

Although the inter-transformation of AgNPs and $\mathrm{Ag}^{+}$has been demonstrated, how this process influence the toxicity of silver remains unclear. It is widely accepted that both AgNPs and $\mathrm{Ag}^{+}$exert toxicity to organisms (Chernousova and Epple, 2013). However, the toxicity of AgNPs comes from AgNPs itself or released $\mathrm{Ag}^{+}$is still controversial (Misra et al., 2012). Some studies believe that AgNPs has distinguished unique toxicity over $\mathrm{Ag}^{+}$(Qian et al., 2013). Pyrosequencing reveals higher impact of AgNPs than $\mathrm{Ag}^{+}$on the microbial community structure of activated sludge from wastewater treatment process (Yang et al., 2014). Truncated triangular silver nanoplates with a lattice plane as the basal plane displayed stronger biocidal action to gram-negative bacterium Escherichia coli than $\mathrm{Ag}^{+}(\mathrm{Pal}$ et al., 2007). Sublethal concentrations of $\mathrm{Ag}^{+}$and AgNPs exposure to Daphnia embryos also revealed that there is an AgNP-specific mitotoxicity to Daphnia magna (Stensberg et al., 2014). AgNP-exposed common grass, Lolium multiflorum, failed to develop root hairs, had highly vacuolated and collapsed cortical cells, which was not observed for $\mathrm{Ag}^{+}$-exposed group (Yin et al., 2011). However, other studies argue that the toxicity of AgNPs mainly comes from the dissolved $\mathrm{Ag}^{+}$. The short term toxicity of AgNPs and $\mathrm{Ag}^{+}$to photosynthesis in Chlamydomonas reinhardtii indicated that the major toxic effect was belonging to $\mathrm{Ag}^{+}$while AgNPs were just acting as the source of $\mathrm{Ag}^{+}$(Navarro et al., 2008). The study by Xiu et al. (2012) recently suggests that antimicrobial activity of AgNP are totally from the dissolved $\mathrm{Ag}^{+}$and the particle-specific antibacterial activity of AgNP is negligible. Although there is still debate in the toxicity of AgNPs and $\mathrm{Ag}^{+}$, it is generally accepted that the toxicity of AgNPs and $\mathrm{Ag}^{+}$is different. Therefore, the inter-transformation of AgNPs and $\mathrm{Ag}^{+}$should have a great impact on the toxicity of silver (Juganson et al., 2013; Shi et al., 2012).

D. magna, as a small-sized filter-feeding freshwater crustacean, is an ideal model organism to evaluate the short-term toxicity of the mixture of $\mathrm{Ag}^{+}$and AgNPs (Allen et al., 2010; Newton et al., 2013; Zhao and Wang, 2012). In this study, the mixture of $\mathrm{Ag}^{+}$and AgNP with varied $\mathrm{Ag}^{+}$fraction was prepared through reduction of $\mathrm{Ag}^{+}$by $\mathrm{NOM}$ under natural sunlight and the acute toxic effect of the mixture of $\mathrm{Ag}^{+}$and AgNP on D. magna was investigated. The formation of AgNPs was demonstrated and characterized by ultraviolet-visible spectroscopy (UV-Vis), high resolution transmission electron microscopy (HR-TEM), energy dispersive spectroscopy (EDS), and selected area electron diffraction (SAED). Furthermore, the fraction of unconverted $\mathrm{Ag}^{+}$was determined by ultrafiltration separation and inductively coupled plasma mass spectrometry (ICP-MS) determination. The acute toxic effect of the mixture of $\mathrm{Ag}^{+}$and AgNP was further investigated by using D. magna as a model. This study is helpful to enrich our knowledge on the environmental transformation of AgNPs and $\mathrm{Ag}^{+}$and the subsequent toxicological effect.

\section{Materials and methods}

\subsection{Reagents and instrumentation}

Silver perchlorate $\left(\mathrm{AgClO}_{4}\right)$ (with $>99.0 \%$ purity) were purchased from Beijing Chemicals (Beijing, China). Suwannee River natural organic matter (SRNOM) was obtained from the International Humic Substances Society (IHSS, St. Paul, USA). The NOM solution was stirred homogenously before passing it through $0.2 \mu \mathrm{m}$ membrane filters (mixed cellulose esters, Millipore Corp., Billerica, USA). The dissolved organic carbon (DOC) of NOM solution was then determined by a Phoenix 8000-persulfate total organic carbon analyzer (TekmarDohrmann, Cincinnati, USA). Nitric acid (65\%) was obtained from Merck (Darmstadt, Germany). The other chemicals were purchased from Sinopharm Chemical Reagent Co. (Beijing, China) (analytically pure or better). Ultrapure water (18.3 M $\Omega$ ) used throughout all the experiments was produced by a Milli-Q Gradient system (Millipore, Bedford, USA). All pH were measured by an ORION 4 STAR pH.ISE benchtop (Thermo Fisher Scientific, Waltham, USA). Before each measurement, the electrode was calibrated by $\mathrm{pH}$ standard solution. Silver concentration was measured by ICP-MS (7700, Agilent, Santa Clara, CA, USA) with silver standard solutions prepared by diluting a certified reference material (BW08610, National Institute of Metrology, Beijing, China) with $5 \%(\mathrm{~V} / \mathrm{V}) \mathrm{HNO}_{3}$.

\subsection{Formation of AgNPs under natural sunlight}

We set three groups of experiment solutions according to the $\mathrm{pH}$ ( $\mathrm{pH} 7.4,8.0$, and 9.0). A $100 \mathrm{~mL}$ sample (NOM (10 mg/L $\mathrm{DOC}), \mathrm{AgClO}_{4}(0.5 \mathrm{mmol} / \mathrm{L})$, borate buffer $\left.(2.5 \mathrm{mmol} / \mathrm{L})\right)$ was added into a $110 \mathrm{~mL}$ quartz bottle covered with quartz 
stopper. The toxicity test (data not shown) suggested that $\mathrm{ClO}_{4}^{-}$ (as $\mathrm{NaClO}_{4}$ ) at $10 \mu \mathrm{g} / \mathrm{L}$ concentration level did not shown any acute toxicity to $D$. magna, indicating in the toxic test the effect of $\mathrm{ClO}_{4}^{-}$can be neglected. At sunlight exposure intervals, the solution was collected (as shown in Table 1), adjusted to $\mathrm{pH} 7.4$, and stored at $4^{\circ} \mathrm{C}$ in the dark before further chemical analysis and toxic test. Dark control experiment was also performed in quartz bottle and the resulting solution was also stored at $4^{\circ} \mathrm{C}$. The intensity of the natural sunlight was measured at 15 min intervals routinely by a LI-192 Quantum Sensor (LICOR Biosciences, Lincoln, USA).

\subsection{Characterization of AgNPs}

UV-Vis spectrum from 200 to $1000 \mathrm{~nm}$ was performed using $1 \mathrm{~cm}$ optical path length quartz cuvettes on a Shimadzu UV-3600 (Kyoto, Japan). HR-TEM, EDS and SAED were acquired using a TEANAI G2 20-200 kV (FEI, Hillsboro, USA) or JEOL 2011 (Herts, England) transmission electron microscope. The sample for HR-TEM was prepared by evaporation of $10 \mu \mathrm{L}$ solution onto a carbon-coated copper grid at room temperature under vacuum.

\subsection{Determination of $\mathrm{Ag}^{+}$concentration in the irradiated solution}

Diluted irradiated solution containing $\mathrm{Ag}^{+}$and AgNPs was mixed with saturated ethylene diamine tetraacetic acid disodium salt ( $\mathrm{Na}_{2} \mathrm{EDTA}$ ) solution to isolate $\mathrm{Ag}^{+}$from $\mathrm{NOM}$, then ultrafiltration centrifugation tube (Amicon Ultra-15 $3 \mathrm{kD}$, Millipore, Billerica, MA, USA) was used to separate $\mathrm{Ag}^{+}$and AgNPs. After centrifugation at $9600 \mathrm{r} / \mathrm{min}$ (9582 g) for $40 \mathrm{~min}$, the filtration containing $\mathrm{Ag}^{+}$was collected and diluted with $5 \%$ nitric acid for ICP-MS analysis. Then, the concentration of AgNPs can be calculated by subtracting $\mathrm{Ag}^{+}$concentration from total silver concentration. The recovery of $\mathrm{Ag}^{+}$in

\begin{tabular}{|c|c|c|c|c|c|}
\hline Sample & $\mathrm{pH}$ & $\begin{array}{c}\text { Cumulative } \\
\text { PAR } \\
\left(\mathrm{E} / \mathrm{m}^{2}\right)\end{array}$ & $\begin{array}{c}\mathrm{Ag}^{+} \\
(\mathrm{mmol} / \mathrm{L})\end{array}$ & $\begin{array}{c}\text { AgNPs } \\
(\mathrm{mmol} / \mathrm{L})\end{array}$ & $\mathrm{Ag}^{+} \%$ \\
\hline Sample 1 & 7.4 & 0.0 & 0.50 & 0.00 & 100 \\
\hline Sample 2 & & 13.9 & 0.40 & 0.10 & 80.1 \\
\hline Sample 3 & & 27.1 & 0.39 & 0.11 & 78.1 \\
\hline Sample 4 & & 44.4 & 0.35 & 0.15 & 69.2 \\
\hline Sample 5 & & 62.5 & 0.32 & 0.18 & 64.4 \\
\hline Sample 6 & & 115.3 & 0.30 & 0.20 & 59.6 \\
\hline Sample 7 & & 155.7 & 0.30 & 0.20 & 59.9 \\
\hline Sample 8 & & 192.8 & 0.30 & 0.20 & 60.2 \\
\hline Sample 9 & & 268.9 & 0.30 & 0.20 & 60.6 \\
\hline Sample 10 & & 306.0 & 0.28 & 0.22 & 56.6 \\
\hline Sample 11 & 8.0 & 0.0 & 0.48 & 0.02 & 96.0 \\
\hline Sample 12 & & 27.1 & 0.26 & 0.24 & 52.4 \\
\hline Sample 13 & & 62.5 & 0.22 & 0.28 & 44.0 \\
\hline Sample 14 & & 155.7 & 0.18 & 0.32 & 36.7 \\
\hline Sample 15 & & 306.0 & 0.18 & 0.32 & 35.1 \\
\hline Sample 16 & 9.0 & 0.0 & 0.27 & 0.23 & 53.6 \\
\hline Sample 17 & & 36.1 & 0.09 & 0.41 & 18.8 \\
\hline Sample 18 & & 73.2 & 0.10 & 0.40 & 20.0 \\
\hline Sample 19 & & 186.4 & 0.06 & 0.44 & 11.7 \\
\hline
\end{tabular}

ultrafiltration was over $98 \%$, indicating the adsorption of $\mathrm{Ag}^{+}$ on the filter is negligible.

\subsection{Test of toxicity to D. magna}

The $8 \mathrm{hr}$-acute toxicity tests were conducted according to OECD guideline (Daphnia sp. Acute immobilization test) (Asghari et al., 2012; Choi and $\mathrm{Hu}, 2008$; Tejamaya et al., 2012) with some changes. The commonly used ecotoxicology media contained $\mathrm{Mg}^{2+}$ and $\mathrm{Ca}^{2+}$, which might lead to the aggregation of AgNPs (Mukherjee and Weaver, 2010). To avoid this shortcoming, in this study, fully aerated $0.1 \mathrm{mmol} / \mathrm{L}$ $\mathrm{NaNO}_{3}$ was used as ecotoxicology media and the test solutions were prepared by diluting the above obtained irradiated samples in the $0.1 \mathrm{mmol} / \mathrm{L} \mathrm{NaNO}_{3}$. Preliminary experiments were conducted to estimate the concentration of silver causing the death of D. magna, and then the effective concentrations were set according to the determined concentration ranges. In the formal tests, ten neonates $(<24 \mathrm{hr})$ were selected randomly and placed in $50 \mathrm{~mL}$ exposure solution in glass beaker covered with plastic breathable membrane. Previous study showed that the presence of algae would affect the toxicity of nanoparticles (Allen et al., 2010), and therefore D. magna was not feed during the exposure. Experiments were performed with three replicates. After $8 \mathrm{hr}$ exposure, the numbers of dead D. magna were counted. All statistical data were processed by SPSS version 12.0 (SPSS Inc., Chicago, IL, USA).

\section{Results and discussion}

\subsection{Sunlight-driven reduction of $\mathrm{Ag}^{+}$to $\mathrm{AgNPs}$ by NOM}

The sunlight-driven reduction of $\mathrm{Ag}^{+}$to AgNPs by SRNOM was investigated under $\mathrm{pH} 7.4,8.0$ and 9.0, respectively. Under sunlight irradiation, the color of the $\mathrm{Ag}^{+}$solution tints yellow slowly, indicating the reduction of $\mathrm{Ag}^{+}$to AgNPs. Clearly, the solution with higher $\mathrm{pH}$ tints yellow faster and deeper than that with lower $\mathrm{pH}$, suggesting the enhanced formation AgNPs at higher $\mathrm{pH}$. The solution was sampled and characterized with UV-Vis spectroscopy at different interval or cumulative photosynthetically active radiation (PAR) (Fig. 1). In Fig. 1, absorption peaks centering at approximate $400 \mathrm{~nm}$ could be observed, which were characteristic of surface plasmon resonance (SPR) of spherical AgNPs. At pH 7.4 (Fig. 1a), the absorbance intensity first increased then decreased and broadened SPR peak was observed with the accumulation of PAR, which suggested larger sized AgNPs or aggregations were formed. In Fig. 1b-c, the intensity of SPR peak were much higher than that in Fig. 1a, indicating the increased concentration of AgNPs. The enhanced formation of AgNPs at higher $\mathrm{pH}$ was ascribed to lower redox potential of NOM at higher $\mathrm{pH}$, which facilitate the formation of AgNPs (Yin et al., 2012). Meanwhile, the maximum absorption wavelength $\left(\lambda_{\max }\right)$ of AgNPs at pH 7.4 red-shifted slightly (Fig. 1a) while the shapes of absorbance spectra of $\mathrm{pH} 8.0$ and 9.0 (Fig. $1 \mathrm{~b}-\mathrm{c}$ ) were almost unchanged, indicating that the AgNPs were more stable at higher $\mathrm{pH}$. This might be due to the stronger stabilization effect of NOM as a capping agent at 

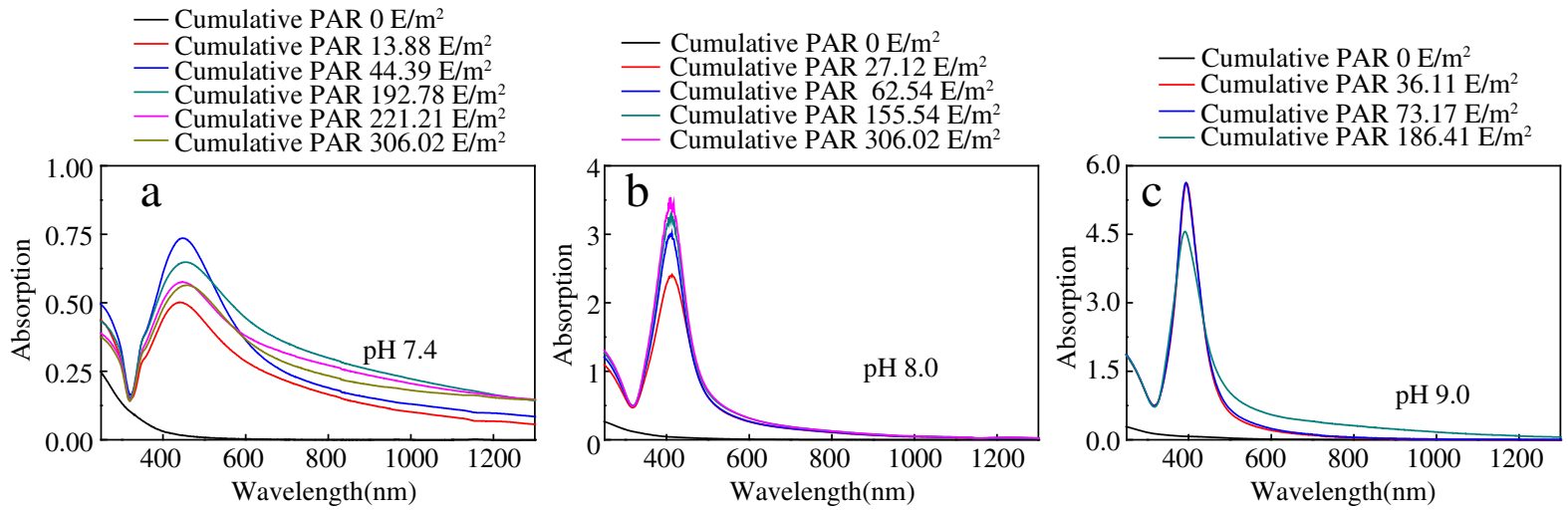

Fig. 1 - Ultraviolet-visible absorption spectrum of mixture solutions containing $0.5 \mathrm{mmol} / \mathrm{L} \mathrm{AgClO}$, $10 \mathrm{mg} / \mathrm{L}$ natural organic matter (NOM) and $2.5 \mathrm{mmol} / \mathrm{L}$ borate buffer under natural sunlight. (a) pH 7.4, (b) pH 8.0, (c) pH 9.0. The cumulative photosynthetically active radiation (PAR) was marked in the figure.

higher $\mathrm{pH}$ conditions owning to the dissociation of phenolic and carboxyl group in NOM. The time-resolved UV-Vis results suggested the reduction of $\mathrm{Ag}^{+}$to AgNPs by NOM was mainly driven by sunlight irradiation.

Selected samples were further characterized for the formation of AgNPs through HR-TEM, EDS, and SAED (Fig. 2). The HR-TEM images (Fig. 2a-c) and the SAED patterns (Fig. 2g-i) could be indexed to face-centered cubic (fcc) metallic silver. EDS images (Fig. 2d-f) also confirmed that the nanoparticles were elemental silver. The high signals of copper were attributed to the carbon supported copper grid. Fig. 2 also clearly demonstrated larger sized AgNPs were formed at lower $\mathrm{pH}$, which is consistent with the UV-Vis results.

\subsection{Fraction of $\mathrm{Ag}^{+}$under varied sunlight irradiation interval and $\mathrm{pH}$ conditions}

As the reduction of $\mathrm{Ag}^{+}$to AgNPs was mainly driven by sunlight and influenced by solution $\mathrm{pH}$, different cumulative PAR (or sunlight irradiation time) and $\mathrm{pH}$ conditions could result in different $\mathrm{Ag}^{+}$or AgNP fractions. Therefore, before toxicity test, the fraction of $\mathrm{Ag}^{+}$in the mixture of $\mathrm{Ag}^{+}$and AgNP was determined by ultrafiltration and ICP-MS and the results are shown in Table 1 and Fig. 3. The fraction of $\mathrm{Ag}^{+}$in total $\mathrm{Ag}$ decreased from $100 \%$ to $56.6 \%$ at $\mathrm{pH} 7.4$, from $96.0 \%$ to $35.1 \%$ at $\mathrm{pH} 8.0$, and from $53.6 \%$ to $11.7 \%$ at $\mathrm{pH} 9.0$ with the increase of cumulative PAR. The formation of AgNPs was also detected with concentration of 0.02 and $0.23 \mathrm{mmol} / \mathrm{L}$ in the solutions without sunlight irradiation (samples 11 and 16) at pH 8.0 and 9.0, respectively, indicating the reduction in the dark at higher $\mathrm{pH}$ (Yin et al., 2012). Fig. 3 shows the cumulative PAR dependent reduction of $\mathrm{Ag}^{+}$into AgNPs by NOM under sunlight at various $\mathrm{pH}$ levels. With the increase of cumulative PAR, the fraction of $\mathrm{Ag}^{+}$decreased significantly. Fig. 3 also shows that minimum $\mathrm{Ag}^{+} \%\left(\mathrm{Ag}^{+} \%_{\text {min }}\right)$ followed: $\mathrm{Ag}^{+} \%_{\text {min }}, \mathrm{pH} 7.4>\mathrm{Ag}^{+} \%_{\text {min }}, \mathrm{pH} 8.0>$ $\mathrm{Ag}^{+} \%_{\min }$ pH 9.0. All the results revealed that the conversion of $\mathrm{Ag}^{+}$to AgNPs increased with elevated solution $\mathrm{pH}$.

\subsection{Toxicity of silver to D. magna}

The above obtained mixture of $\mathrm{Ag}^{+}$and AgNP (samples 1, 2, 4, 7, 15, 17, 19 in Table 1) with varied $\mathrm{Ag}^{+}$fraction (11.7\%-100\%) were selected to expose to D. magna (Fig. 4). We prepared 6 different concentrations for each sample, so each curve in Fig. 4 was fitted by 7 points including the blank control (0.1 mmol/L $\mathrm{NaNO}_{3}$ ). Mortality rate curve for each sample was different while total silver concentration was identical, which showed that the acute toxicity of silver to D. magna does not depend on the concentration of total silver (Newton et al., 2013). Then, 8 hr-LC 50 of each sample was obtained from Fig. 4 through SPSS version 12.0 and the resulting Fig. 5 shows that $8 \mathrm{hr}-\mathrm{LC}_{50}$ decreased from $1.252 \mu \mathrm{g} / \mathrm{L}$ to $0.279 \mu \mathrm{g} / \mathrm{L}$, with the AgNP\% increased from $0 \%$ to $88.31 \%$. These results clearly demonstrated that sunlight-driven reduction of $\mathrm{Ag}^{+}$to AgNPs by NOM decreases the acute toxicity of silver to D. magna. In addition, this result indicated that the acute toxicity of silver to $D$. magna was positively correlated with $\mathrm{Ag}^{+}$, but not AgNPs or total silver.

\subsection{Environmental implications}

Once released into the environment, both AgNPs and $\mathrm{Ag}^{+}$ undergo various chemical transformations, especially oxidative dissolution and reduction. The oxidative dissolution of AgNPs to $\mathrm{Ag}^{+}$is usually believed to increase the toxicity of silver to organism (Misra et al., 2012). The reduction of $\mathrm{Ag}^{+}$by NOM under natural sunlight could decrease the free dissolved $\mathrm{Ag}^{+}$in the solution, although the potential environmental and toxicological impact of this transformation process is still not well understood. Our study clearly demonstrated that the sunlight-driven reduction of $\mathrm{Ag}^{+}$to AgNPs by NOM significantly mitigates the acute toxicity of silver to D. magna. This result reveals that the joint effect of sunlight and NOM in surface water is a natural antidote to the toxicity of AgNPs and $\mathrm{Ag}^{+}$. This study also suggested that other environmental processes possibly influence the oxidative dissolution of 

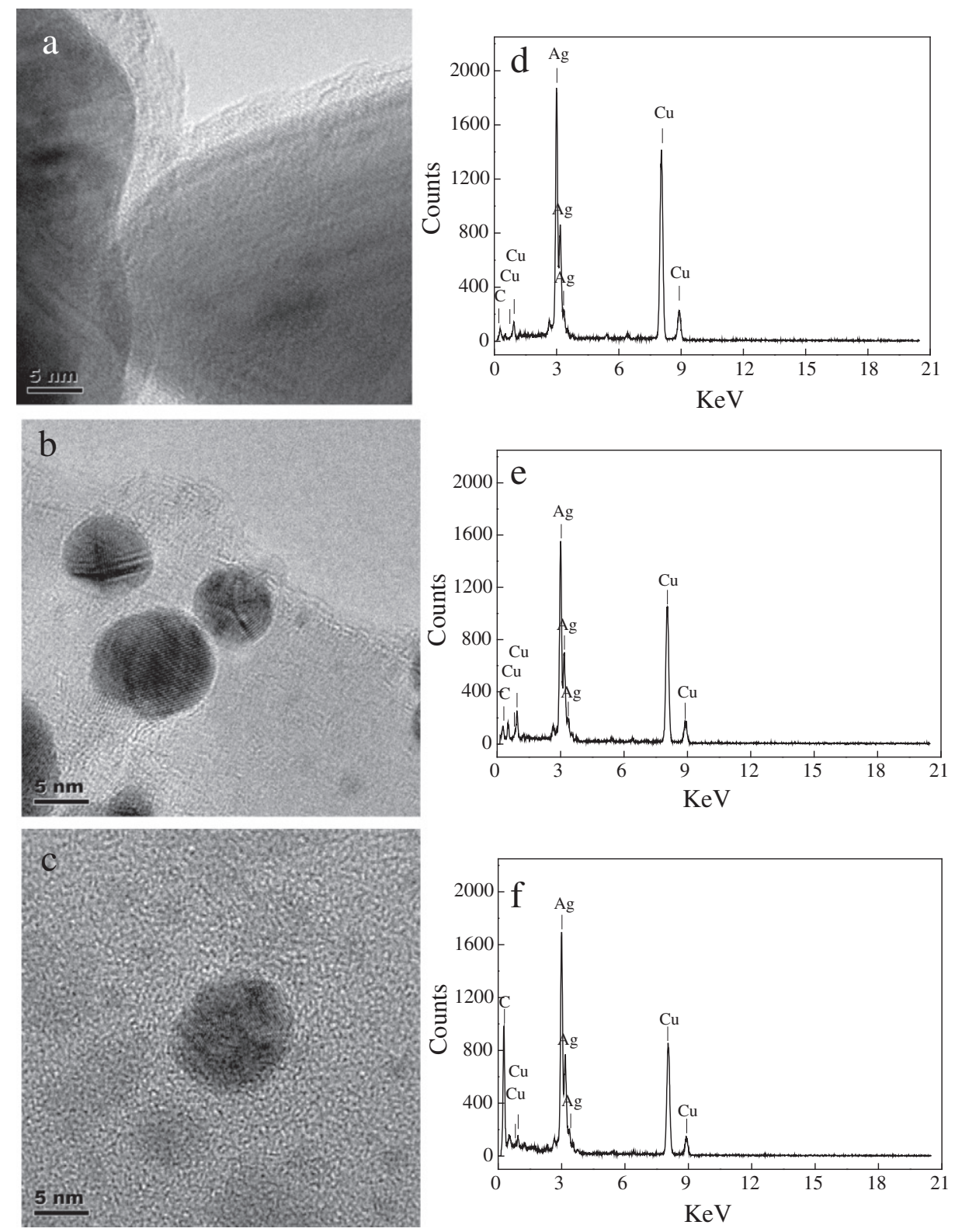
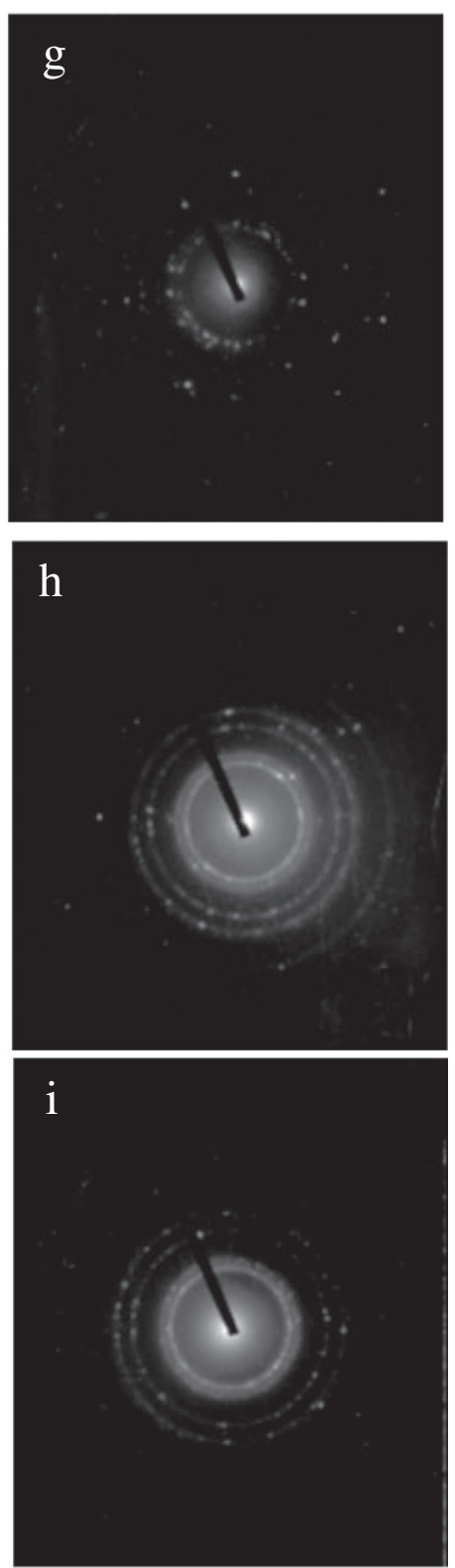

Fig. 2 - Identification and characterization of AgNPs formed in solution containing $0.5 \mathrm{mmol} / \mathrm{L} \mathrm{AgClO} 4,10 \mathrm{mg} / \mathrm{L} \mathrm{NOM}$ and $2.5 \mathrm{mmol} / \mathrm{L}$ borate buffer under natural sunlight by high resolution electron transmission microscopy (a-c), energy dispersive spectroscopy (d-f), and selected area electron diffraction (g-i). (a, d, g) pH 7.4, (b, e, h) pH 8.0, (c, f, i) pH 9.0. The accumulative PARs were 306.02, 27.12, and $36.11 \mathrm{E} / \mathrm{m}^{2}$ for $(\mathrm{a}, \mathrm{d}, \mathrm{g}),(\mathrm{b}, \mathrm{e}, \mathrm{h})$ and $(\mathrm{c}, \mathrm{f}, \mathrm{i})$, respectively.

AgNPs and the reduction of $\mathrm{Ag}^{+}$should also have a great impact on the toxicity of silver. At present, it is still a debate that the toxicity of AgNP comes from itself or the released $\mathrm{Ag}^{+}$. Our results further indicate that the dissolved $\mathrm{Ag}^{+}$from AgNPs played a major role in the acute toxicity of AgNPs.

\section{Conclusions}

In this study, we investigated the reduction process of $\mathrm{Ag}^{+}$ions by NOM under natural sunlight, and subsequent toxic impact of this process to D. magna. The formation of AgNPs was demonstrated by combined characterization techniques. The formation of AgNPs enhanced significantly with increasing the solution $\mathrm{pH}$ and cumulative PAR of sunlight. The acute toxicity test of the mixture of $\mathrm{Ag}^{+}$and AgNP on D. magna demonstrated that the reduction of $\mathrm{Ag}^{+}$by NOM to AgNPs under sunlight significantly mitigated the acute toxicity of silver to D. magna. These results highlight the importance of sunlight and NOM in the fate, transformation and toxicity mitigation of $\mathrm{Ag}^{+}$and AgNPs, and further indicate that the acute toxicity of AgNPs should be mainly ascribed to the dissolved $\mathrm{Ag}^{+}$from AgNPs. 


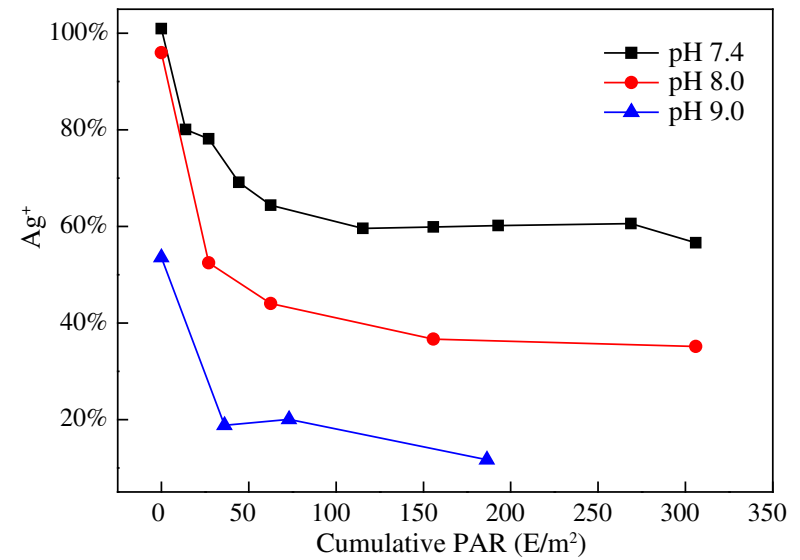

Fig. 3 - Cumulative photosynthetically active radiation (PAR)-dependent reduction of $\mathrm{Ag}^{+}$into $\mathrm{AgNPs}$ by NOM under sunlight at various $\mathrm{pH}$.

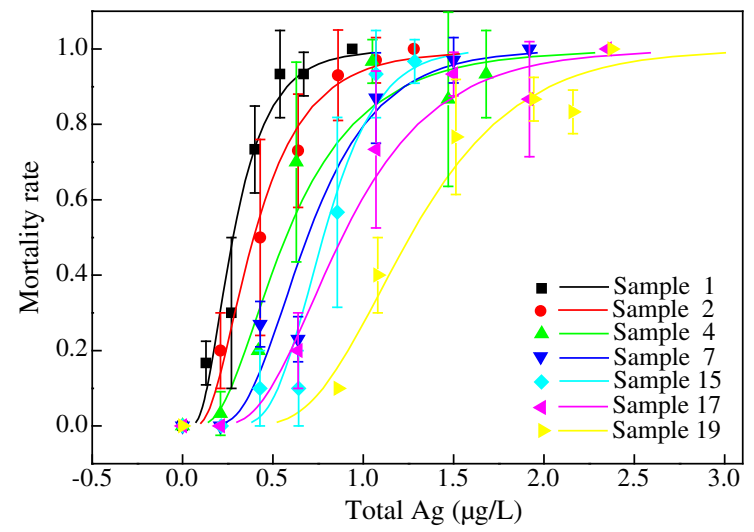

Fig. 4- Effect of total silver concentration in irradiated sample on the mortality rate of Daphnia magna. The information of the samples has been given in Table 1.

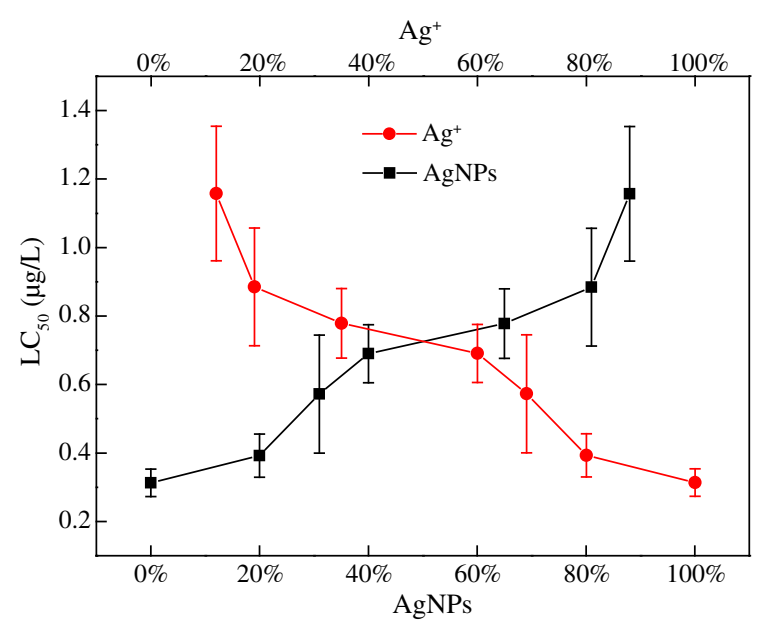

Fig. 5 - Effect of silver nanoparticles (AgNPs) and $\mathrm{Ag}^{+}$fraction in irradiated samples on the $8 \mathrm{hr}-\mathrm{LC}_{50}(\mu \mathrm{g} / \mathrm{L})$ of Daphnia magna. $8 \mathrm{hr}-\mathrm{LC}_{50}$ was expressed as total silver.

\section{Acknowledgment}

This work was supported by the National Science Fund for Distinguished Young Scholars (No. 21025729), the National Natural Science Foundation of China (Nos. 21337004, 21207124) and the Young Scientists Fund of RCEES (No. RCEES-QN20130028F).

\section{R E F E R E N C E S}

Adegboyega, N.F., Sharma, V.K., Siskova, K., Zboňl, R., Sohn, M., Schultz, B.J., et al., 2012. Interactions of aqueous $\mathrm{Ag}^{+}$with fulvic acids: mechanisms of silver nanoparticle formation and investigation of stability. Environ. Sci. Technol. 47 (2), 757-764.

Allen, H.J., Impellitteri, C.A., Macke, D.A., Heckman, J.L., Poynton, H.C., Lazorchak, J.M., et al., 2010. Effects from filtration, capping agents, and presence/absence of food on the toxicity of silver nanoparticles to Daphnia magna. Environ. Toxicol. Chem. 29 (12), 2742-2750.

Angel, B.M., Batley, G.E., Jarolimek, C.V., Rogers, N.J., 2013. The impact of size on the fate and toxicity of nanoparticulate silver in aquatic systems. Chemosphere 93 (2), 359-365.

Asghari, S., Johari, S.A., Lee, J.H., Kim, Y.S., Jeon, Y.B., Choi, H.J., et al., 2012. Toxicity of various silver nanoparticles compared to silver ions in Daphnia magna. J. Nanobiotechnol. 10, 14.

Benn, T.M., Westerhoff, P., 2008. Nanoparticle silver released into water from commercially available sock fabrics. Environ. Sci. Technol. 42 (11), 4133-4139.

Benn, T., Cavanagh, B., Hristovski, K., Posner, J.D., Westerhoff, P., 2010. The release of nanosilver from consumer products used in the home. J. Environ. Qual. 39 (6), 1875-1882.

Chernousova, S., Epple, M., 2013. Silver as antibacterial agent: ion, nanoparticle, and metal. Angew. Chem. Int. Ed. 52 (6), 1636-1653.

Choi, O., Hu, Z., 2008. Size dependent and reactive oxygen species related nanosilver toxicity to nitrifying bacteria. Environ. Sci. Technol. 42 (12), 4583-4588.

Choi, O., Deng, K.K., Kim, N.J., Ross Jr., L., Surampalli, R.Y., Hu, Z., 2008. The inhibitory effects of silver nanoparticles, silver ions, and silver chloride colloids on microbial growth. Water Res. 42 (12), 3066-3074.

Geranio, L., Heuberger, M., Nowack, B., 2009. The behavior of silver nanotextiles during washing. Environ. Sci. Technol. 43 (21), 8113-8118

Hou, W.C., Stuart, B., Howes, R., Zepp, R.G., 2013. Sunlight-driven reduction of silver ions by natural organic matter: formation and transformation of silver nanoparticles. Environ. Sci. Technol. 47 (14), 7713-7721.

Juganson, K., Mortimer, M., Ivask, A., Kasemets, K., Kahru, A., 2013. Extracellular conversion of silver ions into silver nanoparticles by protozoan Tetrahymena thermophila. Environ. Sci.: Processes Impacts 15 (1), 244-250.

Kamat, P.V., 2002. Photophysical, photochemical and photocatalytic aspects of metal nanoparticles. J. Phys. Chem. B 106 (32), 7729-7744.

Kittler, S., Greulich, C., Diendorf, J., Koller, M., Epple, M., 2010. Toxicity of silver nanoparticles increases during storage because of slow dissolution under release of silver ions. Chem. Mater. 22 (16), 4548-4554.

Lam, I.K.S., Wang, W., 2006. Accumulation and elimination of aqueous and dietary silver in Daphnia magna. Chemosphere 64 (1), 26-35.

Lasko, C.L., Hurst, M.P., 1999. An investigation into the use of chitosan for the removal of soluble silver from industrial wastewater. Environ. Sci. Technol. 33 (20), 3622-3626. 
Levard, C., Hotze, E.M., Lowry, G.V., Brown, G.E., 2012.

Environmental transformations of silver nanoparticles: impact on stability and toxicity. Environ. Sci. Technol. 46 (13), 6900-6914.

Li, Q., Mahendra, S., Lyon, D.Y., Brunet, L., Liga, M.V., Li, D., et al., 2008. Antimicrobial nanomaterials for water disinfection and microbial control: potential applications and implications. Water Res. 42 (18), 4591-4602.

Liu, J., Hurt, R.H., 2010. Ion release kinetics and particle persistence in aqueous nano-silver colloids. Environ. Sci. Technol. 44 (6), 2169-2175.

Liu, J., Sonshine, D.A., Shervani, S., Hurt, R.H., 2010. Controlled release of biologically active silver from nanosilver surfaces. ACS Nano 4 (11), 6903-6913.

Misra, S.K., Dybowska, A., Berhanu, D., Luoma, S.N., Valsami-Jones, E., 2012. The complexity of nanoparticle dissolution and its importance in nanotoxicological studies. Sci. Total Environ. 438, 225-232.

Mukherjee, B., Weaver, J.W., 2010. Aggregation and charge behavior of metallic and nonmetallic nanoparticles in the presence of competing similarly-charged inorganic ions. Environ. Sci. Technol. 44 (9), 3332-3338.

Navarro, E., Piccapietra, F., Wagner, B., Marconi, F., Kaegi, R., Odzak, N., et al., 2008. Toxicity of silver nanoparticles to Chlamydomonas reinhardtii. Environ. Sci. Technol. 42 (23), 8959-8964.

Newton, K.M., Puppala, H.L., Kitchens, C.L., Colvin, V.L., Klaine, S.J., 2013. Silver nanoparticle toxicity to Daphnia magna is a function of dissolved silver concentration. Environ. Toxicol. Chem. 32 (10), 2356-2364.

Pal, S., Tak, Y.K., Song, J.M., 2007. Does the antibacterial activity of silver nanoparticles depend on the shape of the nanoparticle? A study of the gram-negative bacterium Escherichia coli. Appl. Environ. Microbiol. 73 (6), 1712-1720.

Qian, H.F., Peng, X.F., Han, X., Ren, J., Sun, L.W., Fu, Z.W., 2013. Comparison of the toxicity of silver nanoparticles and silver ions on the growth of terrestrial plant model Arabidopsis thaliana. J. Environ. Sci. 25 (9), 1947-1955.

Ribeiro, F., Gallego-Urrea, J.A., Jurkschat, K., Crossley, A., Hassellöv, M., Taylor, C., et al., 2014. Silver nanoparticles and silver nitrate induce high toxicity to Pseudokirchneriella subcapitata, Daphnia magna and Danio rerio. Sci. Total Environ. 466-467, 232-241.
Sanudowilhelmy, S.A., Flegal, A.R., 1992. Anthropogenic silver in the southern California bight - a new tracer of sewage in coastal waters. Environ. Sci. Technol. 26 (11), 2147-2151.

Shi, J.P., Ma, C.Y., Xu, B., Zhang, H.W., Yu, C.P., 2012. Effect of light on toxicity of nanosilver to Tetrahymena pyriformis. Environ. Toxicol. Chem. 31 (7), 1630-1638.

Sotiriou, G.A., Meyer, A., Knijnenburg, J.T.N., Panke, S., Pratsinis, S.E., 2012. Quantifying the origin of released $\mathrm{Ag}^{+}$from nanosilver. Langmuir 28 (45), 15929-15936.

Stensberg, M.C., Madangopal, R., Yale, G., Wei, Q., Ochoa-Acuna, H., Wei, A., et al., 2014. Silver nanoparticle-specific mitotoxicity in Daphnia magna. Nanotoxicology 8 (8), 833-842.

Tang, B., Sun, L., Li, J.L., Zhang, M.W., Wang, X.A., 2015. Sunlight-driven synthesis of anisotropic silver nanoparticles. Chem. Eng. J. 260, 99-106.

Tejamaya, M., Römer, I., Merrifield, R.C., Lead, J.R., 2012. Stability of citrate, PVP, and PEG coated silver nanoparticles in ecotoxicology media. Environ. Sci. Technol. 46 (13), 7011-7017.

Xiu, Z., Zhang, Q., Puppala, H.L., Colvin, V.L., Alvarez, P.J.J., 2012. Negligible particle-specific antibacterial activity of silver nanoparticles. Nano Lett. 12 (8), 4271-4275.

Yang, Y., Quensen, J., Mathieu, J., Wang, Q., Wang, J., Li, M.Y., et al., 2014. Pyrosequencing reveals higher impact of silver nanoparticles than $\mathrm{Ag}^{+}$on the microbial community structure of activated sludge. Water Res. 48, 317-325.

Yin, L., Cheng, Y., Espinasse, B., Colman, B.P., Auffan, M., Wiesner, M., et al., 2011. More than the ions: the effects of silver nanoparticles on Lolium multiflorum. Environ. Sci. Technol. 45 (6), 2360-2367.

Yin, Y.G., Liu, J.F., Jiang, G.B., 2012. Sunlight-induced reduction of ionic Ag and Au to metallic nanoparticles by dissolved organic matter. ACS Nano 6 (9), 7910-7919.

Yu, S.J., Yin, Y.G., Chao, J.B., Shen, M.H., Liu, J.F., 2013. Highly dynamic PVP-coated silver nanoparticles in aquatic environments: chemical and morphology change induced by oxidation of $\mathrm{Ag}^{\mathrm{O}}$ and reduction of $\mathrm{Ag}^{+}$. Environ. Sci. Technol. 48 (1), 403-411.

Zhao, C.M., Wang, W.X., 2012. Size-dependent uptake of silver nanoparticles in Daphnia magna. Environ. Sci. Technol. 46 (20), 11345-11351. 